\title{
DAMAGE ASSESSMENT OF RCC STRUCTURE USING NON - DESTRUCTIVE TESTS
}

\author{
Athar Hussain \\ Associate Professor, Department of Civil Engineering, \\ Ch. Brahm Prakash Government Engineering College, Jaffarpur, New Delhi, India. \\ Taukeer \\ M.Tech. Student, Civil Engineering Department, Environmental Engineering Section, \\ School of Engineering, Gautam Buddha University, Greater Noida, U.P., India. \\ Rashid Shams, Inder Kumar Yadav, Saurabh Kumar \\ U.G. Student, Department of Civil Engineering, \\ Ch. Brahm Prakash Government Engineering College Jaffarpur, New Delhi, India.
}

\begin{abstract}
Most of the existing buildings, which do not fulfill the current or code based requirements, may suffer extensive or even collapse if shaken by a severe earthquake. The aim of evaluation is to assess the vulnerable or damaged buildings for future use. The assessment may also be helpful for intervention required in seismically deficient buildings. The need of damage identification is continuously growing for the maintenance of existing civil infrastructure. Safe performance of bridges, dams, nuclear plants, and important multistoried buildings is vital to the human race and its economics. Structures continuously accumulate damage during their service life. Damage to structures caused by hazards such as earthquakes and windstorms, and after long-term ageing may be natural. For the purpose of assuring seismic safety, it is necessary to monitor for, occurrence, location, and extent of damage. Identification of a single cause of damage to buildings is not possible. There are combined reasons which are responsible for multiple damages. Hence, this study is aimed at conducting damage assessment of a $(G+9)$, multi-storeyed residential building, badly damaged due to corrosion, cracks, deterioration of concrete and presence of moisture. The building was constructed in the year 2001, used for residential purpose for almost 8 years. Then the building was not used for some years. This damage assessment study is conducted using non-destructive tests.
\end{abstract}

\section{Keywords - Watermarking, Haar Wavelet, DWT, PSNR}

\section{INTRODUCTION}

The need of damage identification is continuously growing for the maintenance of existing civil infrastructure. Structures continuously accumulate damage during their service life. Damage to structures caused by hazards such as earthquakes and windstorms, and after long-term ageing may be natural. Undetected damage may potentially lead to more serious damage and eventually to catastrophic failure. Hence, rapid structural damage detection is essential. There is always a need to have a relationship between the damage that occurred in the structure and its dynamic characteristics to ascertain its current health status. There are combined reasons responsible for the damage and deterioration of buildings.

In RCC structures there are many types of damages that can take place. Concrete is a major constituent of an RCC structure. Concrete is the most versatile material man made material of recent past because of its ability to take any shape but it has certain limitations like lower flexure, tensile strength, poor bond between old and hardened concrete to new and fresh concrete. Damages in RCC structure includes spalling, delamination's, cracking etc. Deterioration of concrete has significant effect on the performance and serviceability of structures. Many factors can contribute to the deterioration of concrete structures such as; poor construction, overloading, aging, corrosion of steel, chemical reactions, natural disasters, etc. Unfortunately, damage assessment is a time consuming process with serious effect on structural capacity and durability.

This paper is motivated towards the identification and assessment of damage of main structural components of the building using non-destructive tests. Qualitative assessment methods are used which aims to identify weak points in the structure. Damage assessment has been carried out using visual inspection and non-destructive testing techniques. 


\section{International Journal of Engineering Applied Sciences and Technology, 2019 Vol. 4, Issue 6, ISSN No. 2455-2143, Pages 108-113 \\ Published Online October 2019 in IJEAST (http://www.ijeast.com)}

\section{PRoBlem STATEMENT}

The building under consideration is a G+9, multistory residential building developed by Ghaziabad development authority(GDA). It is located in Vaishali, Ghaziabad, U.P., India. Damages in this building includes reinforcement corrosion, cracks in concrete, spalling. It also hosts leaking pipes, de-laminations in columns, beams corners located at different heights, beam soffits, slab soffits, leached plaster on parapets corroded and leaking drainage pipes, RCC masonry wall interfaces cracks in masonry in-fills even complete crumbling at some places, heavy de-bonding and dismantling of plaster at both exterior and interior surfaces etc. These were further damaged by the rain and environmental conditions. Due to fast deterioration, it was decided to assess the damage and find its health condition and future life span of the buildings at the earliest.

\section{LITERATURE REVIEW}

The research works carried by various scientists, scholars, students concerning the "Damage Assessment of Multi-storey RCC Structures" are discussed. This section of the paper gives a comprehensive review of the work carried out by various researchers in the field of damage assessment of buildings. The theoretical background in the literatures will be used as the basis in conducting the works of the research.

Varinder K. Singh in his paper studied pertaining to the early repair and rehabilitation work. He considered a case of G+8 building damaged due to corrosion of reinforcement. Extensive assessment was carried out and cracks were repaired by filling grout. Another group of researchers Kanwar Varinder, Kwatra Naveen et.al, studied pertaining to the repair and rehabilitation work to be done after an earthquake. They employed periodic monitoring using vibrational measurements as non-destructive testing method. status of the buildings has been discussed in this paper.The study starts with the need of damage identification in existing buildings. Damage in this study is defined as stiffness reduction of one or more elements of a structure which leads to change in the dynamic aspects like frequency, mode shape etc. (Housner and Masri, 1997). The application of non-destructive tests was further highlighted by R. Jain Namitha and Vishwanath K.N, they studied study the applicability, performance, availability, complexity and restrictions of NDT. Non-destructive tests like Ultrasonic Pulse Velocity and Rebound Hammer were performed to assess the quality/strength of in-situ concrete in $\mathrm{RC}$ members at all accessible regions of the building in all the blocks.

Kumar Sanjeev, Akhter Saleem et. al, also studied related to the effective evaluation and assessment methods. He concluded though NDT has been used as used for more than three decades for monitoring concrete structures; now it has been recognized that NDT plays an important role in the condition monitoring of RCC structures. He also listed out major advantages and limitations of NDT. Matthew $\mathrm{H}$. Banville, PE; Authors have stressed upon the need to determine the cause and extent of damage, description of how the building is constructed, the strength of materials used and the intended purpose of the individual building components. The condition survey includes the types and width of cracks, joints, delaminations, spalling, water infiltration, exposed steel, corrosion, structural distress, NDT (field testing), destructive field testing. The authors have also highlighted the methods of concrete repair, surface repair of concrete, crack repairs etc.

Rasel Munshi Md. and Asif Md. et. al; presented the retrofitting process of the existing structures in accordance with seismic considerations. The objective was to evaluate existing buildings earthquake performance. The building was applied with dead, live and earthquake load and analyzed using STAAD pro. Steel Plating Retrofitting Method was applied for the beams and Concrete Jacketing Retrofitting Method was applied for the columns. From the above study it may be said that the buildings which were not built with seismic consideration can be evaluated and retrofitted following the latest building codes. Whereas, Kahya et.al. studied pertaining to the damages on RCC structures due to two consecutive earthquakes near van city, Turkey.it was observed and concluded that failures are due to weak bond between concrete and steel, weak ground stories, deficiency of shear reinforcement and strong beam and weak column mechanism.

\section{METHOD AND METHODOLOGY NON- DESTRUCTIVE EVALUATION}

There are occasions when the various performance characteristics of concrete in a structure are required to be assessed. In most of the cases, an estimate of strength of concrete in the structure is needed, although parameters like overall quality, uniformity, etc, also become important in others. The various methods that can be adopted for in-situ assessment of strength properties of concrete depend upon the particular aspect of strength in question.

\section{REBOUND HAMMER TEST}

A simple electronic equipment called Rebound Hammer or Schmidt Hammer is used for this purpose. The schematic diagram of operation of rebound hammer is given 


\begin{tabular}{|l|l|}
\hline Average rebound no. & \multicolumn{1}{|c|}{ Quality of concrete } \\
\hline$>40$ & Very good hard layer \\
\hline 30 to 40 & Good layer \\
\hline 20 to 30 & Fair \\
\hline$<20$ & Poor concrete \\
\hline 0 & Delaminated \\
\hline
\end{tabular}

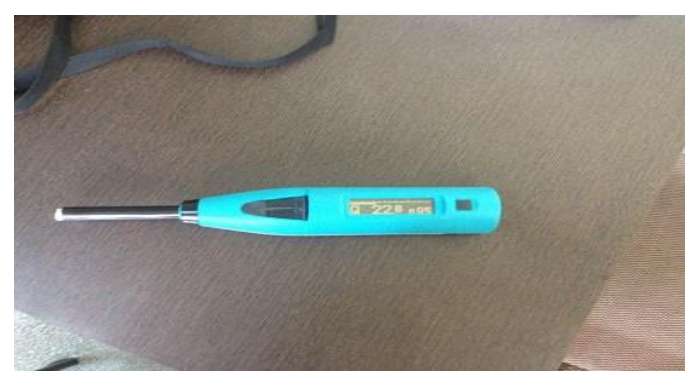

Figure 1: Rebound Hammer

As per IS 13311-2 (Part 2) Method of non-destructive testing of concrete- methods of test, part 2 Rebound Hammer;

As per IS 13311-2; when the plunger of rebound hammer is pressed against the surface of the concrete, the spring controlled mass rebounds and the extent of such rebound depends upon the surface hardness of the concrete. The surface hardness and therefore the rebound is taken to be related to the compressive strength of the concrete. The rebound is send along a graduated scale and is designated as the rebound number or rebound index.

The test requires a smooth surface and a number of readings to cut down variations. The test is not suitable on spalled concrete surfaces of distressed structures, while the comparison of rebound hammer numbers indicate the near surface hardness of the concrete and will help to locate relative surface weakness in cover concrete and also to determine relative compressive strength of concrete. Location possessing very low rebound number indicate a weak surface concrete and such surfaces will be further investigated for more defects of concrete, due to other reasons. The survey is carried out on identified locations in a proper way by making locations into grid points. The locations have a spacing of approximately $300 \mathrm{~mm} \times 300 \mathrm{~mm}$.

(Source: IS: 1331-2)

\section{ULTRA SONIC PULSE VELOCITY TEST (UPV)}

Ultra sonic pulse velocity is a scanning type instrument, which passes rays through the specimen to be tested. As per IS 13311 (Part 1) Method of non-destructive testing of concretemethods of test, part 1Ultrasonic Pulse Velocity. The Ultra Sonic Pulse Velocity method could be used to establish;

a) The homogeneity of the concrete,

b) The presence of cracks, voids and other imperfections,

c) Changes in the structure of the concrete which may occur with time.

d) The quality of the concrete in relation to standard requirements.

e) The quality of one element of concrete in relation to another, and

f) The value of dynamic elastic modulus of the concrete.

\section{PROCEDURE OF THE TEST}

This test consists of measuring travel time ' $\mathrm{T}$ ' of ultrasonic pulse of $50-54 \mathrm{kHz}$, produced by an electro-acoustical transducer, held in contact with one surface of the concrete member under test and receiving the same by a similar transducer in contact with the surface at the other end. With the path length ' $L$ ', the distance between the two probes, and time of travel, $\mathrm{T}$, the pulse velocity $(\mathrm{V}=\mathrm{L} \div \mathrm{T})$ is calculated. Higher the elastic modulus, density and integrity of the concrete, higher is the pulse velocity. The ultrasonic pulse velocity depends on the density and elastic properties of the material being tested. The pulse velocity in concrete may be influenced by;

a) Path length (The influence of path length will be neglected if it is less than $100 \mathrm{~mm}$, for $20 \mathrm{~mm}$ size aggregates or less than $150 \mathrm{~mm}$ for $40 \mathrm{~mm}$ size aggregates.)

b) Lateral dimensions of the specimen tested.

c) Presence of the reinforcement.

d) Moisture.

Measurement of pulse velocities at points on regular grid on the surface of concrete structure provides efficient technique of assessing the homogeneity of the concrete. The size of the grid chosen depends on the structure and the amount of variations obtained. 
The below table provides guidelines for qualitative assessment of concrete based on UPV test results;

Table no. 3.16: Velocity Criterion for Concrete Quality Grading

\begin{tabular}{|c|c|c|}
\hline Sl. No. & $\begin{array}{c}\text { Pulse velocity by cross } \\
\text { probing }(\mathbf{k m} / \mathbf{s e c})\end{array}$ & $\begin{array}{c}\text { Concrete Quality } \\
\text { Grading }\end{array}$ \\
\hline 1 & Above 4.5 & Excellent \\
\hline 2 & 3.5 to 4.5 & Good \\
\hline 3 & 3.0 to 3.5 & Medium \\
\hline 4 & Below 3.0 & Doubtful \\
\hline
\end{tabular}

(Source: IS 1331- Part 1: 1992)

\section{EXPERIMENT AND RESULT}

The results of tests carried out on columns, walls of the building during the damage assessment period are discussed below. It also covers the discussion on the test results obtained., data collected from the field survey and from various literatures, used in this study.

\section{STRUCTURE OBSERVATION ON VISUAL INSPECTION}

1. Visual inspection of the building indicated heavy corrosion due to environmental attacks.

2. At certain locations of beams, columns, and slabs concrete cover had got spalled and some shear stirrups on the outside face of columns in basement were totally eaten up by corrosion.

3. Cracking and spalling, cracking and rust staining or rust on reinforcement in 1-4 floors of the building is visible and this is mainly because of corrosion of steel in concrete.

4. At most columns in the ground floor and first floor cracks were seen running along the reinforcement location and cracking along the bar is an important indication that the reinforcement is subjected to corrosion.

5. At right angles to main reinforcement cracks were seen, these cracks are generally because of structural deficiency.

6. Beam - column junctions were badly cracked indicating irregularities in load on columns because of design failure.

7. At the first floor a big hole in slab was found and reinforcement of that portion is hanging. This has happened because the partition walls of the above floors had broken down and fallen in that part of the slab.
8. Every partition walls in between each floor are seen broken and completely fallen into pieces. A number of columns had continuous vertical cracks along the line of concrete cover thickness.

9. The sideways of staircases of ground floor and first 4 floors are completely damaged and the first step in the staircase leading to second floor is completely missing/damaged. Reinforcement of this step is seen hanging.

10. At terrace floors of the building, spalling of concrete is seen. On inspection it was found that rainwater disposal system was not properly provided, hence stagnation occurred and its effect visible to naked eye.

11. At some locations architectural and design failure is seen.
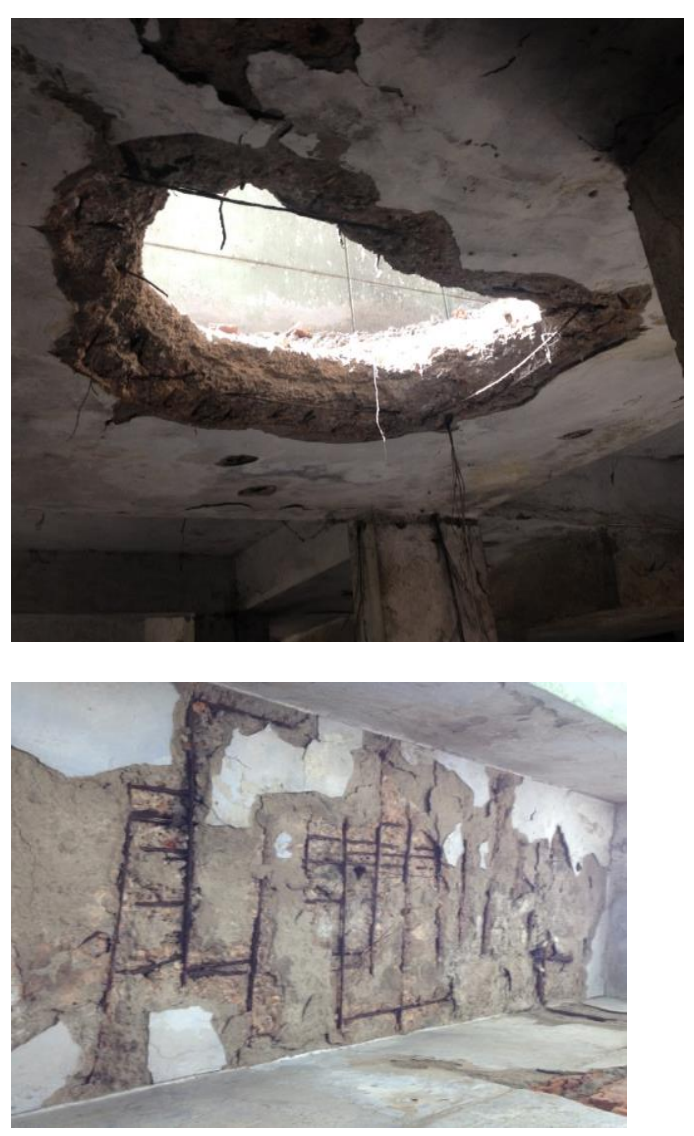

\section{NON-DESTRUCTIVE TEST RESULTS}

Non-destructive tests (Schmidt rebound hammer and pulse velocity tests) are performed to assess the quality of existing materials without damaging the existing structures. The Schmidt rebound hammer is principally a surface hardness tester which works on the principle that the rebound of an elastic mass depends on the hardness of the surface against which the mass impinges. 
The test results are presented in tabular form for the columns of soft/stilt storey and columns supporting the water tank as well. It is seen that the pulse velocities vary from $1666 \mathrm{~m} / \mathrm{s}$ to $3353 \mathrm{~m} / \mathrm{s}$ and rebound numbers vary from 12 to 52 with a large variation in the results in different locations of a column. Same variation has been noticed in the results between the columns indicating the in homogeneity of concrete and spurious quality of its ingredients having deleterious materials like excessive silt, high $\mathrm{pH}$ water etc. Some of the results of pulse velocity are below $3.0 \mathrm{~km} / \mathrm{s}$ which indicate the 'doubtful' quality of the concrete as per clause 7.1.1, Table 2, IS 13311 (1) as shown below. The results obtained by conducting Schmidt hammer and UPV test on beams and columns on different floors are summarized in tables below.

Rebound hammer values obtained for columns, beams and slab are shown below in tabular form;

Table No. 1 Quality of concrete test by pulse velocity

\begin{tabular}{|c|c|c|}
\hline Sl. No. & $\begin{array}{c}\text { Pulse velocity by } \\
\text { cross probing } \\
\text { (km/sec) }\end{array}$ & $\begin{array}{c}\text { Concrete Quality } \\
\text { Grading }\end{array}$ \\
\hline 1 & Above 4.5 & Excellent \\
\hline 2 & 3.5 to 4.5 & Good \\
\hline 3 & 3.0 to 3.5 & Medium \\
\hline 4 & Below 3.0 & Doubtful \\
\hline
\end{tabular}

Table No. 2 Rebound hammer value for columns.

\begin{tabular}{|c|c|c|c|c|}
\hline \multirow{2}{*}{$\begin{array}{c}\text { N } \\
\mathbf{O}\end{array}$} & \multicolumn{4}{|c|}{ Rebound Hammer Value (Columns) } \\
\cline { 2 - 5 } & Reading 1 & Reading 2 & Reading 3 & Reading 4 \\
\hline $\mathbf{1}$ & $20,22,26,20$ & $10,16,30,22$ & $28,22,25,26$ & $21,23,26,29$ \\
\hline $\mathbf{2}$ & $26,26,26,30$ & $28,25,25,22$ & $22,22,26,26$ & $23,23,26,26$ \\
\hline $\mathbf{3}$ & $32,30,32,34$ & $22,22,26,20$ & $20,20,26,28$ & $20,24,26,26$ \\
\hline $\mathbf{4}$ & $16,16,16,20$ & $25,25,26,28$ & $28,22,22,26$ & $26,26,26,28$ \\
\hline
\end{tabular}

Table No. 3 Rebound Hammer Value for Beams

\begin{tabular}{|c|c|c|c|c|}
\hline \multirow{2}{*}{$\begin{array}{c}\text { S. } \\
\text { N }\end{array}$} & \multicolumn{4}{|c|}{ Rebound Hammer Value (Beams) } \\
\cline { 2 - 5 } O & Reading 1 & Reading 2 & Reading 3 & Reading 4 \\
\hline $\mathbf{1}$ & $28,28,22,26$ & $22,22,26,26$ & $22,28,28,28$ & $\begin{array}{c}30,32,32, \\
30\end{array}$ \\
\hline
\end{tabular}

\begin{tabular}{|c|c|c|c|c|}
\hline $\mathbf{2}$ & $30,32,32,31$ & $26,29,26,30$ & $26,18,16,20$ & $\begin{array}{c}25,28,16, \\
22\end{array}$ \\
\hline $\mathbf{3}$ & $26,22,20,20$ & $26,22,22,28$ & $28,28,16,16$ & $\begin{array}{c}18,25,31, \\
29\end{array}$ \\
\hline $\mathbf{4}$ & $28,15,25,28$ & $28,22,26,18$ & $18,16,22,18$ & $\begin{array}{c}25,28,22, \\
26\end{array}$ \\
\hline
\end{tabular}

Table No. 4 Rebound Hammer Value for Slab

\begin{tabular}{|c|c|c|c|c|}
\hline \multirow{2}{*}{ S.NO } & \multicolumn{4}{|c|}{ Rebound Hammer Value (Beams) } \\
\cline { 2 - 5 } & Reading 1 & Reading 2 & Reading 3 & Reading 4 \\
\hline $\mathbf{1}$ & $12,12,16,10$ & $16,16,10,12$ & $16,18,18,20$ & $\begin{array}{c}16,18,20, \\
20\end{array}$ \\
\hline $\mathbf{2}$ & $22,25,27,26$ & $28,28,28,30$ & $22,28,28,28$ & $\begin{array}{c}18,25,25, \\
26\end{array}$ \\
\hline $\mathbf{3}$ & $16,16,20,15$ & $22,26,20,28$ & $30,32,38,34$ & $\begin{array}{c}28,32,38, \\
40\end{array}$ \\
\hline $\mathbf{4}$ & $42,42,42,46$ & $32,38,46,52$ & $48,46,40,48$ & $32,30,36$, \\
& & & & 35 \\
\hline
\end{tabular}

UPV test values obtained for columns, beams and slab are shown below in tabular form;

Table No.5 Pulse velocity for Beams

\begin{tabular}{|c|c|c|}
\hline \multirow{2}{*}{$\begin{array}{c}\text { S. } \\
\text { No }\end{array}$} & \multicolumn{2}{|c|}{ Pulse Velocity m/s } \\
\cline { 2 - 3 } & Reading 1 & Reading 2 \\
\hline 1 & 1661 & 3011 \\
\hline 2 & 2760 & 2811 \\
\hline 3 & 2003 & 2420 \\
\hline
\end{tabular}

Table No. 6 Pulse velocity for Columns

\begin{tabular}{|c|c|c|}
\hline \multirow{2}{*}{ S. No } & \multicolumn{2}{|c|}{ Pulse Velocity m/s } \\
\cline { 2 - 3 } & Reading 1 & Reading 2 \\
\hline 1 & 2490 & 2604 \\
\hline 2 & 1994 & 3353 \\
\hline 3 & 1824 & 1823 \\
\hline
\end{tabular}




\section{International Journal of Engineering Applied Sciences and Technology, 2019 \\ Vol. 4, Issue 6, ISSN No. 2455-2143, Pages 108-113 \\ Published Online October 2019 in IJEAST (http://www.ijeast.com)}

\section{CONCLUSION}

Based on the visual survey, non-destructive test results, conducted on the building the following conclusions can be made. The cause of cracks/damage were found because of varying loads, poor grade of concrete. The reinforcement in columns was not adequate and of good quality. The cracks/damage to the structure has left it unsafe. A bit of substandard quality of concrete and poor quality of shuttering used. The quality of construction used was not as per standards and process of construction was not supervised by qualified engineers. The values of pulse velocity and rebound hammer of non-destructive tests have shown large variations which indicate the inconsistency in the concrete used for the construction. There is no substitute for good quality of concrete construction practices. The quality control of materials and workmanship must be strictly checked at the site. Poor practices of construction cannot be rectified at later stage except repeated costly retrofitting to keep structure functional. The structural design needs to be revised for a high rise building like the one under study. The damaged components have to be re-designed/repaired/retrofitted/recasted depending upon the degree of damage.

\section{REFERENCES}

1. Aggarwal and Shirkande, 2013, "Earthquake resistant design of structures", PHI learning private limited.

2. CPWD, 2012 "Hand book on repair and rehabilitation of RCC buildings" New Delhi.

3. D. M Mccann et. al., "Review of NDT method in the assessment of concrete and masonry structures", ELSEVIER, 34, 2001-71-84.

4. IS 1331 part 1, 1992, "Non-destructive testing of concrete. Methods of test", Part 1 Ultrasonic pulse velocity, Bureau of Indian Standards, New Delhi.

5. IS 1331 part 2, 1992, "Non-destructive testing of concrete. Methods of test", Part 2, Rebound hammer test, Bureau of Indian Standards, New Delhi.

6. IS 1893 (Part 1): 2002, "Criteria for earthquake resistant design of structures", Bureau of Indian Standards.

7. IS 456:2000, "Plain and reinforced concrete - Code of practice", Bureau of Indian Standards.

8. IS 6925-1973, "Methods of test for determination of water soluble chlorides in chlorine admixtures", Bureau of Indian Standards, New Delhi.

9. Matthew H-Banville, PE, (2008)"Assessment and repair of concrete structures", RCI'S $23^{\text {rd }}$ International convention and trade show.

10. Munshi Md. Rasel et. al., (2015) "Retrofitting process of an existing building with respect to seismic considerations in Bangladesh", International Journal of scientific and engineering research.

11. N. Krishna Raju, 2012, "Advanced reinforced concrete design" PHI learning Pvt. limited.
12. Namitha et. al.,(2013) "Strength assessment and restoration of RCC structures.", International journal of engineering research \& technology (IJERT) July.

13. Sambu Narayan et. al., (2011) "Assessment of buildings for damage resistance", Malaysian Journal of Civil engineering, 23(1)-86-104.

14. R. Ditommaso et al., "Damage localisation on RCC structures", DiSGG, University of Basilicate, Italy.

15. Sinha Ravi et al., "Seismic vulnerability assessment of buildings and procedure for Rapid visual screening of buildings for potential seismic vulnerability".

16. S.K Duggal, 2014, "Earthquake resistant design of structures", Oxford University Press.

17. Sanjeev et. al., (2013) "Review of Non-destructive testing methods for condition monitoring of concrete structures.", Journal of construction Engineering,

18. Saurabh et al., "Visual seismic damage states for reinforced concrete frame-shear wall buildings", $11^{\text {th }}$ Canadian conference on Earthquake engineering.

19. Standard methods of water and waste water examination 2000.

20. Varinder. K. Singh, (2013) "Structural repair and rehabilitation of multi-storeyed rcc building", Procedia Engineering 51, pages (55-64).

21. Varinder Kanwar, Naveen Kwatra and Pankaj Aggarwal, (2007)"Damage detection for framed RCC buildings using ANN modelling" International Journal of damage mechanics.

22. Young j. Park et al., (1988) "Seismic damage analysis of reinforced concrete buildings", Proceedings of ninth world conference on Earthquake engineering, Tokyo-Japan August (vol. III). 